\title{
CONCEPT FOR A PERSONA DRIVEN RECOMMENDATION TOOL FOR PROCESS MODELLING APPROACHES
}

\author{
Helten, Katharina (1); \\ Eckert, Claudia (2); \\ Gericke, Kilian (3); \\ Vermaas, Pieter (4) \\ 1: Vitesco Technologies GmbH; \\ 2: The Open University; \\ 3: University of Rostock; \\ 4: Delft University of Technology
}

\begin{abstract}
In order to ensure successful product development processes, manifold modelling approaches have been developed, which cover a wide range of aspects such as responsibilities, duration of activities and dependencies. Still, an industry standard does not exist. Users of process modelling approaches are driven by different targets depending on the respective role. Currently, practitioners need to evaluate strengths and weaknesses of each approach by themselves and find little guidance for the selection.

As a consequence, users might select unsuitable approaches and do not get the expected result. Thus, the intended applications of the model such as analyses or an optimization of the process are hampered. This could heavily affect companies' success by product or project failures.

The paper shows the concept of a recommendation tool that enables a suitable and effective selection of process modelling approaches. Key element is the description of relevant use cases and personas that represent the various needs of both different company types as well as different roles within such as process modellers and users. By identifying the most relevant case, each practitioner will be successfully guided to the most suitable modelling approach.
\end{abstract}

Keywords: Design process, Process modelling, Design practice, Recommendation tool, Personas

\section{Contact:}

Helten, Katharina

Vitesco Technologies GmbH

BU Sensing \& Actuation, Thermal Management Actuation

Germany

katharina.helten@vitesco.com

Cite this article: Helten, K., Eckert, C., Gericke, K., Vermaas, P. (2021) 'Concept for a Persona Driven Recommendation Tool for Process Modelling Approaches', in Proceedings of the International Conference on Engineering Design (ICED21), Gothenburg, Sweden, 16-20 August 2021. DOI:10.1017/pds.2021.71 


\section{INTRODUCTION}

Successful product development requires a deep understanding of underlying engineering processes. Such an understanding is usually built by analysing past and ongoing activities (the actual process) and by modelling these processes. There is a plethora of process modelling methods and tools which have been developed for specific purposes, each with their own strengths and weaknesses. Even though these modelling approaches are well described, an industry-standard does not exist. Consequently, it is difficult for practitioners to select the appropriate approach to address a specific individual problem. Each modelling approach allows capturing some aspects of engineering processes very easily, while capturing other aspects it is less useful. For example, a flowchart shows no time indications, and a Gantt chart focuses less on dependencies. Using an unsuitable tool can frustrate practitioners and bias the outcome. In the worst case, an approach neither models the engineering processes appropriately nor analyses them in ways that lead to process efficiency and improvement. The need for understanding and analysing a process depends not only on the product being designed and the organisation in which the design process happens but also on the role of the person interacting with the model. People interacting with a process model are not necessarily designers nor necessarily able to model the process themselves. Processes that are relevant for the successful execution of a design project may range from, e.g. design processes to procurement, manufacturing or business processes. Thus, people interacting with these models can range from engineers to project managers, to salespersons, general management or even suppliers and customers.

As a result of this process modelling landscape and the diversity of model users, no single process modelling approach is currently able to address all users' needs. This leads to unsatisfactory access to relevant information for a minority of the users in most cases and the use of modelling approaches unsuitable for most model users in the worst case. As process models are the basis for decisionmaking, the consequences of poorly informed decisions can affect the development project's outcome, thus affecting the company.

The Design Process Special Interest Group within the Design Society is working on a recommendation tool intended to facilitate practitioners with effectively selecting suitable modelling approaches. This recommendation tool aims to provide easy and user-friendly access to different approaches and supporting material. This paper outlines the main elements of the intended tool and focuses on describing the various relevant roles and purposes of practitioners as modellers in personas. The aim is to enable practitioners to recognise their specific situation and get guidance.

After giving an overview of the state-of-the-art and the methodology in use, section 4 outlines the general vision of the recommendation tool. In section 5, the intended use cases and personas are described. The results of the two first interviews with industry representatives are reflected afterwards before the paper ends with a summary and an outlook.

\section{STATE-OF-THE-ART}

A variety of modelling approaches have been developed over time, often not targeted at product development processes. These were meant to serve different purposes, such as (Browning et al. 2006):

- $\quad$ Project visualisation (Actions, interactions and commitments; Customised views)

- $\quad$ Project planning (Making commitments; Choosing activities; Structuring the process)

- Project execution and control (Monitoring commitments; Assessing progress; Re-directing; Replanning)

- Project development (Continuous improvement; Organization learning and knowledge management; Training; Compliance)

The main process modelling approaches are: Flowcharts; Integrated Definition Methods (IDEF0, IDEF3) (Knowledge Based Systems Inc. 2010); Gantt Diagrams (Gantt 1919), network planning techniques (Kerzner 2013); Design Structure Matrix (DSM) (Eppinger \& Browning 2012); and Signposting (Clarkson \& Hamilton 2000).

Besides their main purpose (intended use of the model, which is created using the modelling approach respectively the underlying modelling notation), modelling approaches differ concerning the level of detail (Browning 2010), modelling formalism and notation (Gericke et al. 2016), and the variety of entities incorporated in the model (Kreimeyer 2009, Browning et al. 2006). Entities typically covered by different modelling approaches include, e.g. responsibilities (persons, roles, departments), duration 
of activities, required resources, dependencies (e.g. between activities), deadlines, progress of work, deliverables, confidence into estimates and forecast regarding duration, cost.

Each modelling approach has its strengths and limitations affecting its suitability to support process modelling (O'Donovan et al. 2005; Amigo et al. 2013). Model builders should be aware of those limitations and the information needs of potential model users (which presumes that they are aware of their model users). As models are simplifications of reality, model users should be aware of model limitations or being made aware by the modeller by communicating model purpose, assumptions and limitations. This awareness of limitations of modelling approaches by modeller and model user will help to avoid that models are used for inappropriate purposes. However, limitations of modelling approaches are insufficiently communicated, and recommendations of suitable use scenarios are usually missing.

This proliferation of different types of process models is also reflected in the practice of individual companies. Different stakeholders use a variety of modelling approaches depending on their purposes. An interview study in an automotive company (Eckert and Clarkson, 2010) showed that engineers used a multitude of formal and informal modelling approaches to structure and plan their processes. Individual engineers had simultaneously multiple models and combined them on an ad hoc basis to make decisions. They had brought experience with different modelling approaches from different previous organisations and departments. Many were not familiar with any formal modelling approach and just made their own modelling combinations as they went along. While some people actively define processes and create process models, others are only the recipients of processes, which affects how models are interpreted (see Stacey et al., 2020). What modelling approach is appropriate does not only depend on the purpose of the model but also the skills and knowledge of the process modeller and process users (Gericke et al., 2016). However, despite the importance of choosing a modelling approach that fulfils the needs of model users, to date, little guidance exists for selecting suitable modelling approaches.

\section{METHODOLOGY}

The overall structure of the recommendation tool presented in this paper has its origin in the Design Process Special Interest Group of the Design Society's work. At a two-day workshop in Rostock, Germany, in February of 2020, twenty representatives from both academia and industry explored options for benchmarking process modelling approaches. The industry representatives come from several large German engineering companies. Some have direct responsibility for process modelling, while others use process models in their daily work routine. The academic participants are active in design research with a focus on supporting engineering practices. Quantitative measures to compare process modelling approaches were assessed to be of less use to industry; therefore, more qualitative means for recommending specific modelling approaches was required for industry. Hence based on practical experience, use cases of process modelling were identified in terms of use scenarios, and the different roles in industry involved in these use cases were captured by personas. While the paper does not claim that the list of scenarios is exhaustive, the SIG members advanced the chosen scenarios as capturing prominent use cases in industry. For each scenario/persona pair, criteria were formulated that process modelling approaches should meet. Suitable criteria are presented in a companion paper at this conference (Trauer et al., 2021). The first authors of both papers carried out two interviews with industry practitioners to gain feedback on the scenarios, personas and criteria.

\section{TOWARDS A PROCESS MODEL RECOMMENDATION TOOL}

The recommendation tool aims to support different types of users in the selection of a suitable modelling approach and to build a community of practice around process modelling, where users can ask questions and share experiences. There is a multitude of different software tools for process modelling. However, these are based on a small number of different process modelling approaches mentioned in section 2 .

\subsection{General vision}

The general vision is that the recommendation tool guides the users in an interactive way towards suitable modelling approaches. The tool incorporates two layers, as is shown in Figure 1. 
- Situation analysis: The company environment is captured and categorised through use cases, personas and selection criteria. Depending on the size of the company and the main (process) challenge, users need different models and tools to optimise their processes. For example, a startup with a small number of employees in the field of a new mobility device needs different guidance compared to a large and established company with numerous predefined processes in a mature sector such as plant construction. In each use case, different roles follow different goals and interact with each other. For example, somebody responsible for the R\&D department with deliverables such as 3D designs and drawings has other challenges than the IT department that supports R\&D by providing an appropriate process tool and infrastructure. The different user perspectives are summarised with the term "persona". Different criteria apply for each of the possible combinations of use case and persona (Trauer et al., 2021). Examples of criteria include effort, scalability and linkability to databases. The approaches are mapped with the criteria on a generic base, enabling selecting a proper modelling approach. Thus, an expert team assesses to what extent a certain modelling approach meets the criteria. For the selection, the ranked top 5 criteria (by weight) of each persona are multiplied with the assessment to what extent the modelling approach realises the criteria.

- Community of practice: The interaction between the users and the tool makes the user an active part of the selection process. This includes examples for and from practitioners, which are more accessible and credible for people in industry than the often simplistic examples used in academia. For building a community of practice around process modelling, the tool provides users with the option to ask questions to the community and to share lessons learned. This is very important since users might seek guidance but at the same time like to share their own experiences.

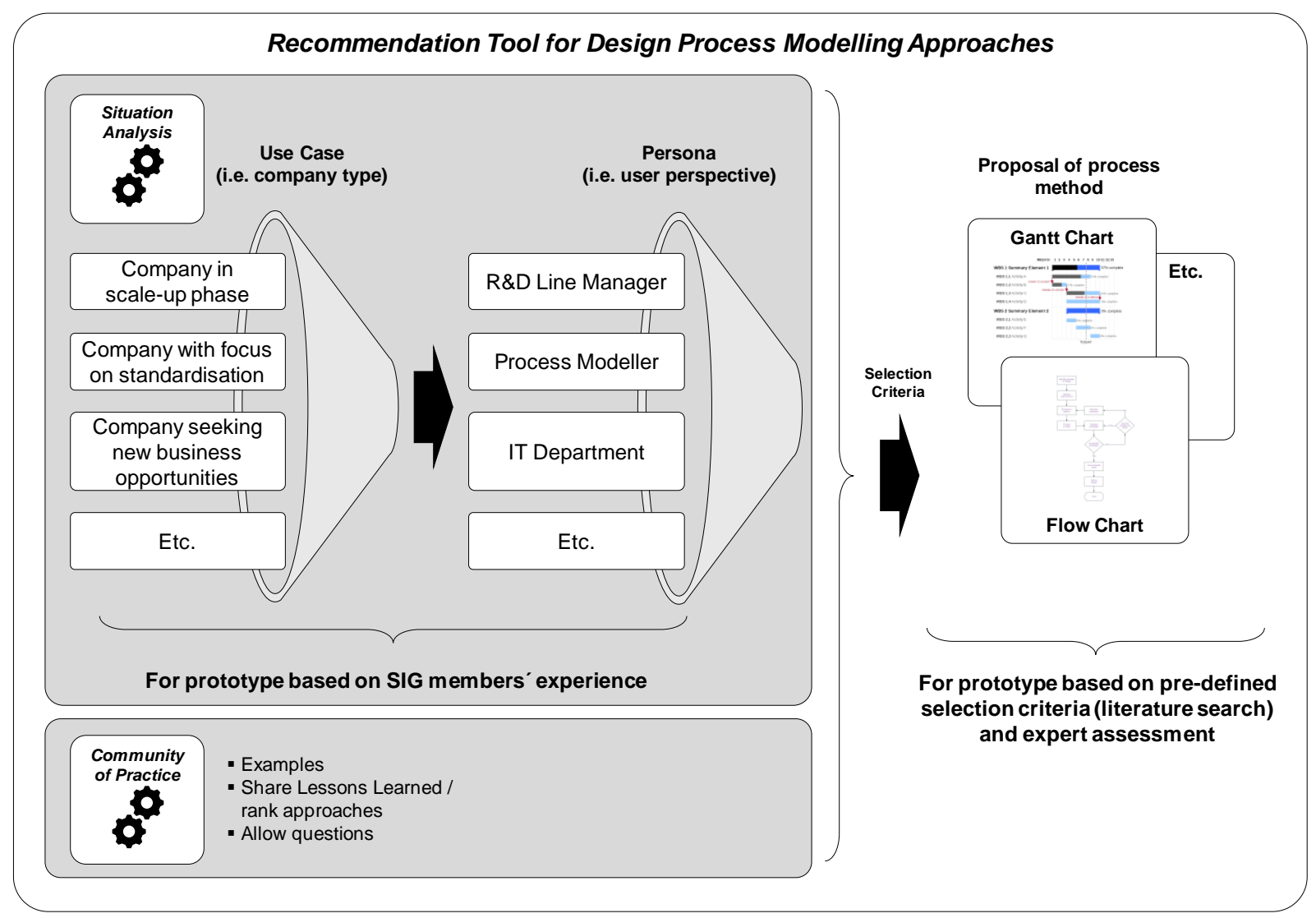

Figure 1. Overall vision of recommendation tool and prototype application

The development of the tool starts with a simple prototype to test and improve the tool's analytics. The first step filters for use cases (currently four), the second for the personas (four per use case). The user will select in both categories the ones that apply. As a result, a specific process modelling approach is proposed. For the prototype, the selection criteria and their specific characteristics are predefined for each persona based on literature and experience of the SIG members. Thus, initially, it is assumed that 
for a single persona, the characteristics can clearly be defined. Later, the prototype will be improved by feeding the collected users experiences back into the descriptions of the characteristics of the personas.

\section{USE CASES AND PERSONAS}

\subsection{Overview of use cases and personas and rationale for their selection.}

The recommendation tool should cover a wide range of companies and challenges within the companies to be of use to industry. Companies were ordered by their size, varying from a small company in a scaleup phase with only a few roles and with the main target to increase the level of maturity of both products and processes, to large-sized companies with a long history in their field and the challenge to either establish a higher level of collaboration and standardisation or to identify new business opportunities in addition to running products and services. Whereas the group of small companies mainly targets the increasing number of start-up companies that deal with new topics such as mobility and Internet of Things, the group of large-sized companies in this paper focuses on established business and products as in the plant engineering or automotive sector. The main driver for companies to look for further business opportunities is currently the increasing level of digitisation and resulting innovations. Personas were in turn ordered by their functional roles, running from overall management to engineering design, control and manufacturing. The description of the personas is still coarse-grained. They will be personalized in order to enhance the user-friendliness of the recommendation tool. Table 1 gives an overview of all use cases and personas that are considered for the prototype.

Table 1. Overview of use cases and personas

\begin{tabular}{|c|c|c|c|c|c|}
\hline & Use Case & \multicolumn{4}{|c|}{ Persona } \\
\hline I & $\begin{array}{c}\text { Companies in } \\
\text { Scale-Up Phase }\end{array}$ & Co-Founder & $\begin{array}{c}\text { Design } \\
\text { Engineer }\end{array}$ & Controller & $\begin{array}{c}\text { Manufacturing } \\
\text { Engineer }\end{array}$ \\
\hline II & $\begin{array}{c}\text { Companies that need to } \\
\text { improve collaboration }\end{array}$ & $\begin{array}{c}\text { R\&D Line } \\
\text { Manager }\end{array}$ & IT Department & $\begin{array}{c}\text { Design } \\
\text { Engineer }\end{array}$ & $\begin{array}{c}\text { Process } \\
\text { Modeller }\end{array}$ \\
\hline III & $\begin{array}{c}\text { Companies with focus on } \\
\text { standardisation }\end{array}$ & $\begin{array}{c}\text { Project } \\
\text { Management } \\
\text { Office }\end{array}$ & $\begin{array}{c}\text { R\&D Line } \\
\text { Manager }\end{array}$ & Quality & $\begin{array}{c}\text { Process } \\
\text { Modeller }\end{array}$ \\
\hline IV & $\begin{array}{c}\text { Companies seeking new } \\
\text { business opportunities }\end{array}$ & $\begin{array}{c}\text { Segment } \\
\text { Head (P\&L) }\end{array}$ & $\begin{array}{c}\text { Marketing \& } \\
\text { Sales }\end{array}$ & $\begin{array}{c}\text { Process } \\
\text { Manager }\end{array}$ & IT Leader \\
\hline
\end{tabular}

\subsection{The use case of companies in the scale-up phase}

The following narrative captures the first use case of smaller companies in the scale-up phase. The company consists of about 50 employees and was founded by two former colleagues three years ago. A very hands-on mentality characterised the first years to get first prototypes built for investors and manufacture up to 100 samples a year. However, customer requests and the number of employees are increasing. Customers include established companies with already existing processes at the interface. As the company is growing, it needs to formalise its processes and can no longer trust that everybody knows how the processes work. Therefore, they need to define the should-be process and track the asis process within the company.

Four personas and their needs can be discerned in this first use case:

- Co-Founder - Gate adherence: One of the co-founders started some benchmark activities. As she is responsible for the whole company, she feels that comprehensive process modelling is needed that depicts all relevant business sub-processes. The aim is to have a clear understanding of the required deliverables and product maturity for specific gates and who is responsible. After the first prototype and seed phase, the company needs to look closely at compliance and standards, such as for safety. That is why the analysis needs also show which documents are requested to pass a gate successfully.

- Design Engineer - Formalisation of specific processes: Although the design engineer has been working in the company for over a year, he struggles with the increasing number of new engineers joining the design department. Due to the increasing number of customers and projects, processes and procedures need to be defined. Previously it had been possible to get deep 
feedback about customer wishes "on the fly" because everyone shared one single office. Now more formal sub-processes need to be defined. How do the design engineers get the requirements from the customer side, and how do they manage them? In the case of different customer applications, how does the company ensure the change and configuration management? A further point is design for manufacturing - which processes are used to enable cross-functional work? Both areas could produce separate deliverables or follow a common review process to ensure a single and aligned outcome. E.g., the communication to a supplier might need an alignment to avoid misunderstandings.

- Controller - Profitability: The controller oversees all value streams and judges on profitability. The company has gained stability now, and main customers have been acquired. However, the times of trial-and-error are over - profit and budget are more in focus now. Of course, some areas have more money to spend, but are the proportions appropriate? In order to have reliable data, the accounting process needs to be set up.

- Manufacturing Engineer - Supplier selection: Besides questions of design for manufacturing, operations engineers always face the challenge of having needed material on-time and with the requested quality in-house. However, due to the increasing number of samples, a second-source supplier needs to be selected. Even though some rough criteria were defined, ensuring quality throughout the process, no formal process was agreed upon. How does the process of supplier pre-selection look like? What are the basic requirements a supplier needs to fulfil? Which internal gates and reviews ensure that incoming components and material fulfil the requirements? It is time to define the procurement and sampling process.

\subsection{The use case of companies that need to improve collaboration}

Process management is quite established in the company. Every team has described main activities, outcomes and responsibilities. However, over the years, these descriptions became very comprehensive and detailed. Even experts in their field sometimes have problems in finding documents quickly. As product development phases become shorter, a new mode of working needs to be identified. People want to improve collaboration and work in a more agile manner. The extensive use of digital tools also requires new behaviours. The following four personas have been identified:

- $\quad$ R\&D Line Manager -Virtual collaboration: Five different sites are working on the current project. Every location uses different tools and processes for planning and tracking the process. Some $\mathrm{R} \& \mathrm{D}$ areas work in a very traditional way in which the team leaders coordinate all project tasks verbally with their team members but lack proper tracking. Other R\&D teams work primarily virtually. They use calls and need to share their desktops. The R\&D line manager has to manage various tools and processes to ensure a good outcome on the interfaces between departments. An overview of topics, processes, tools, outcomes, and important interfaces is needed.

- IT Department - Digitisation: People change their working style. Since more and more people work in global project teams, many IT tools needed to be upgraded. Digital tools are becoming more important such as shared desktops or shared task lists. Traditional ways such as tables that can only be changed by one project manager are no longer accepted. People want to work more intuitively and more cooperatively. The IT department needs to analyse new needs, behaviours and wishes. An application needs to meet the requirements and standards of social media apps the engineers have become familiar with.

- Design Engineer - Duplication of work: As a member of the project team, the design engineers face more time pressure than ever. However, instead of focusing on relevant work packages, they need to generate much documentation and fill in forms without understanding their necessity. Process tailoring is needed to meet the milestones. An overview of all project tasks in R\&D could be beneficial to avoid duplication of work. Sometimes, it is difficult to follow-up on tasks because a designer does not know who is working on them in another location.

- Process Modeller - Guidance: Having managed to describe many detailed processes in the past, the process modeller wants to ensure that engineers have faster and easier access to relevant process descriptions. The workflows need to be simple to understand and apply. New approaches, such as agile and lean engineering, need to be incorporated into the standard process. The target is a smooth transition to get the buy-in of all stakeholders. 


\subsection{The use case of companies with a focus on standardisation}

This is a company with more than 100.000 employees and with a long history. Over the last 25 years, more and more locations have been integrated mainly by acquiring other smaller companies. Besides different locations, the company has different business divisions and business units. All of them develop mechatronic products. Thus, each business unit has comparable but different departments, processes, tools - and challenges. To stay competitive, the company needs to push standardisation, avoid duplication and re-use of existing approaches. The following personas have been identified:

- Head of the Project Management Office (PMO) - Variability of procedures: The project managers need to work across business units for some projects. However, due to missing standards and the resulting high variation of procedures within each area, steering the project effectively is almost impossible. The project managers ask for support. The PMO sets up several workshops to identify current shortcomings and define processes focusing on gate, review and release management. The processes in each site need to be modelled in order to allow a comparison.

- $\quad$ R\&D Line Manager - Synchronisation: One business unit leads the projects, i.e., integrating all necessary sub-components into the final customer project. The R\&D line manager of that business unit is annoyed about the level of alignment and synchronisation between R\&D across sites. The business units have different processes and use different design tools (CAD / CAE) and PDM systems. The way design reviews are conducted in terms of participants and methods and how technical project leads track the R\&D also vary significantly. Main deliverables as the outcome of the design process are not the same. The level of maturity of sub-components is not clear or how it was reached.

- Quality - Compliance: The process responsible is not involved in the daily project work but needs to ensure that the company fulfils all relevant compliance standards such as Automotive SPICE or safety norms such as ISO 26262. He knows that designers often ignore it. However, even under time pressure, projects require a smooth and aligned process. Due to the missing standards across the business units, no one has a good overview of the deliverables and how they interconnect on the sub-component level.

- Process Modeller - Guidance: In order to ensure a standardised and common process between all sub-companies, the processes need to be aligned between all different stakeholders. An attempt to gain an overview of applied modelling approaches, tools and naming conventions has revealed significant gaps in understanding. The discussions are even more complicated since the different areas also use different modelling approaches what makes a quick comparison difficult. Once aligned, the workflows need to be simple to be understandable and applied. As a new challenge, the management also wants to implement agile approaches in all areas. The target is a smooth transition to get the buy-in of all stakeholders and hence a step-by-step integration into the standard processes.

\subsection{The use case of companies seeking new business opportunities}

The company has been a market leader for more than 50 years. Times are changing, and new technologies challenge the existing products. To remain competitive, the company needs urgently to understand the value stream and its opportunities. In order to enhance the existing products by additional features, e.g. by the Internet of Things and Digital Twin applications, new data-driven business models need to be analysed. At the same time, the increasing digitalisation of the company's business processes needs to be managed. The IT infrastructure needs to be revised. The following personas have been identified:

- $\quad$ Segment Head (Profit \& Loss) - Business Opportunities: In the company, the different areas and disciplines have worked in parallel for the last years. To improve and find new competitive products and business models, a holistic analysis of product functionalities is accompanied by an overview of processes, responsibilities and deliverables. Especially, it needs to be identified where and how product-related data can be captured along the whole product lifecycle. This covers aspects of the early product definition phase, such as diagnosis requirements and data from operations to improve product robustness.

- Marketing \& Sales - Potential of data analytics: Thanks to new products and services made partially possible by the Internet of Things, the sales department is working on entirely new 
pricing models. Analyses in other companies have shown to what extent data analytics could be used to monitor the product functionalities. Customer satisfaction could be increased instantly by improved maintenance. With the help of design thinking approaches, the sales team wants to understand the customer benefits better. The modelling of value creation networks indicating which stakeholders contribute to product development plays a major role in this context.

- Process Manager - Digitised workflows: The digitalisation massively increases, data becomes the main focus. This is challenging because the first paperless workflows have only been established one year ago. Reviews, project tracking and other key activities are not done on electronic tools. Nevertheless, KPI have to be generated to manage the overall processes. Many departments are now using different tools, but the toolchain has not been revised on a generic level. Most likely, the range of applied tools can be simplified and aligned.

- $\quad$ IT Leader - Data availability and storage: The IT department needs to analyse which data sources are available during the whole product life cycle. Some overview models exist on different levels and for different purposes, but now a more holistic approach is needed. When and through which devices is data acquired? How is the data stored and analysed? Most likely, many processes are at least partially performed manually. Another critical aspect is also the volume and storage of data. The engineers in the company would like to store all data, but some limitations need to be considered.

The different use cases and the different personas in it all have different needs they want to realise with process modelling approaches, see Table 2. As indicated, this is the first set of personas; the recommendation tool, by enabling practitioners to share their experiences in selecting modelling approaches, collects feedback for improving on the description of use cases and personas and adding new ones.

Table 2. Overview of targets and analysis units for each persona

\begin{tabular}{|c|c|c|c|}
\hline Use Case & Persona & $\begin{array}{l}\text { Target of process } \\
\text { modelling }\end{array}$ & Relevant process element / aspect \\
\hline \multirow{4}{*}{$\begin{array}{l}\text { I Companies in } \\
\text { Scale-Up Phase }\end{array}$} & Co-Founder & Gate adherence & Tasks, gates, interdependencies, compliance \\
\hline & Design Engineer & $\begin{array}{l}\text { Formalisation of specific } \\
\text { processes }\end{array}$ & $\begin{array}{l}\text { Tasks, configuration and change management, } \\
\text { deliverables and methods such as DFM }\end{array}$ \\
\hline & Controller & Profitability & Profit, budget, spendings \\
\hline & Manufacturing Engineer & Supplier selection & $\begin{array}{c}\text { Deliverables, lead time, selection criteria, delivered } \\
\text { quality }\end{array}$ \\
\hline \multirow{4}{*}{$\begin{array}{l}\text { Il Companies that } \\
\text { need to improve } \\
\text { collaboration }\end{array}$} & $\begin{array}{l}\text { R\&D Line Manager for } \\
\text { different locations }\end{array}$ & Virtual collaboration & $\begin{array}{l}\text { Task tracking, interfaces, } \\
\text { variety of process models and tools }\end{array}$ \\
\hline & IT Department & Digitisation & $\begin{array}{l}\text { User interaction, available tools, } \\
\text { integration into IT landscape }\end{array}$ \\
\hline & Design Engineer & Duplication of work & $\begin{array}{c}\text { Deliverables / required documentation, roles, } \\
\text { responsibilities }\end{array}$ \\
\hline & Process Modeller & Guidance & $\begin{array}{l}\text { User acceptance, process models, intergration of new } \\
\text { approaches }\end{array}$ \\
\hline \multirow{4}{*}{$\begin{array}{l}\text { III Companies with } \\
\text { focus on } \\
\text { standardisation }\end{array}$} & $\begin{array}{c}\text { Head of Project } \\
\text { Management Office (PMO) }\end{array}$ & Variability of procedures & Tasks, gates, deliverables, interdependencies \\
\hline & R\&D Line Manager & Synchronisation & $\begin{array}{l}\text { CAD / CAE / PDM tools, review criteria, } \\
\text { design methods, task tracking }\end{array}$ \\
\hline & Quality & Compliance & Standards, deliverables, interdependencies \\
\hline & Process Modeller & Guidance & $\begin{array}{l}\text { Modelling approaches, tools, stakeholders, } \\
\text { integration of new approaches }\end{array}$ \\
\hline \multirow{4}{*}{$\begin{array}{l}\text { IV Companies } \\
\text { seeking new } \\
\text { business } \\
\text { opportunities }\end{array}$} & Segment Head (P\&L) & Business opportunities & Process steps, responsibilities, deliverables, tools \\
\hline & Marketing \& Sales & Potential of data analytics & Data, product functionalities \\
\hline & Process Manager & Digitised workflow & Tools (analog / digital), standardised tool chain \\
\hline & IT Leader & $\begin{array}{l}\text { Data availability and } \\
\text { storage }\end{array}$ & Data storage and access \\
\hline
\end{tabular}




\section{FEEDBACK AND DISCUSSION}

An initial feedback loop with two practitioners (both with general responsibility for processes in their companies) showed the following aspects to be crucial for improving the recommendation tool.

\subsection{Selection of modelling approaches}

The interviewees liked the idea of mapping criteria for specific modelling approaches. One interviewee proposed to let the tool explicitly show the criteria that apply for the specific selected use case and persona and enable the user to adjust the criteria. So, e.g. a process modeller might agree or disagree with the selected and prioritised criteria assigned to his type of persona. Depending on the individual changes, a different process modelling approach could be proposed by the tool. Besides an active interaction, this would allow the opportunity to cover more user types than the predefined personas.

Currently, the prototype does not differentiate the level of expertise of a single user. Practitioners' feedback shows the importance to allow different entry path into the tool depending on the expertise. A newcomer to the field needs more examples and templates to get inspired, whereas a more experienced user looks for very specific details and support. In other words, for a newcomer, the interaction elements such as the sharing of questions and lessons learned could be very relevant.

\subsection{Description of use cases and personas}

The interviewees felt that the use cases and personas covered the main aspects and relevant stakeholders. They liked the differentiation between process modellers and process users since the two groups have different targets and requirements. They also highlighted the need to meet legal standards and certifications with the engineering processes. In many sectors, processes need to be compliant to requirements such as CMMI and Automotive ASPICE for all projects of a company. To manage the trade-off between usability and quality standards is the task of all personas.

\subsection{Supporting material}

Simple templates would be useful to allow a fast application of a specific modelling approach proposed by the tool. Even though many companies would need to integrate the approach into their tool landscape, a fast application is very helpful. Especially for users, who do not have access to a comprehensive tool landscape or little experience with process modelling, it would increase the recommendation tool's acceptance if it provides simple templates (MS Powerpoint or Visio) to maximise user acceptance of the recommendation tool.

At all times, companies face the challenge of integrating new approaches into the existing process landscape, such as agile engineering and design thinking. Since in industry many people struggle with main terms and workflows of those new approaches and their implications, and the people in charge of processes face the need to explain the benefit to their organisations, one interviewee would also like to be provided with arguments and best practices for the integration of such new approaches by the recommendation tool.

The recommendation tool is intended as an independent, neutral platform for the community of process modellers and does not aim to sell specific software tools from tool vendors. Moreover, it is impossible to cover all commercially available tools. Nevertheless, software tools are essential and often decisive criteria for practitioners. One option to cover the need for more guidance would be to allow tool-based lessons learned and examples as a tool element in the community discussion area.

\subsection{User interaction}

The interviewees agreed that users want to play an active part in the recommendation tool to identify with the results and the proposals. One example is a community discussion that allows the sharing of best practices and advice. Consequently, some parts of the tool would need moderation and guidance to keep the tool easily accessible and provide guidance in case of questions.

\section{SUMMARY AND OUTLOOK}

The paper investigates the need to provide more guidance to practitioners in the selection process of an appropriate process modelling approach. Based on literature research and results from a workshop of 
academics and practitioners, the idea of a recommendation tool is generated. In order to enable efficient access to the high amount of modelling approaches, the authors describe the need to differentiate use cases and personas and show exemplary the relevance of four specific use cases with four personas in each of them. A first round of interviews with practitioners showed both the high relevance and the usefulness of the presented approach.

In a next step, the described use cases and personas need to be mapped, based on the criteria developed in (Trauer et al., 2021), to different process modelling approaches and tested again by presenting the recommendation tool to users. The testing could provide an interactive option, as suggested by one of the interviewees. Further, the early feedback, as described in section 6 , needs to be integrated.

Afterwards, the prototype of the recommendation tool can be set up to allow feedback and further improvements. In the beginning, users could get access to the tool and get interviewed by the researchers to understand better user requirements after a phase of application. In the long run, it will then be necessary to run a study with a much higher number of users. After applying and interacting with the tool, an automated and anonymous questionnaire would help to gain feedback.

The iteration loop with users will most likely lead to more extensive libraries of use cases and personas. This will enable users to navigate the recommendation tool better and to use it in a more targeted way.

\section{REFERENCES}

Amigo, C. R., Iritani, D. R., Rozenfeld, H. and Ometto, A. (2013) 'Product Development Process Modeling: State of the Art and Classification', in Abramovici, M. and Stark, R. (eds) Smart Product Engineering, Proceedings of the 23rd CIRP Design Conference. Bochum, Germany: Springer, Heidelberg, pp. 169-179. doi: 10.1007/978-3-642-30817-8-17.

Browning, T.R., Fricke, E. \& Negele, H., 2006. Key concepts in modeling product development processes. Systems Engineering, 9(2), pp.104-128.

Browning, T.R., 2010. On the alignment of the purposes and views of process models in project management. Journal of Operations Management, 28(4), pp.316-332.

Clarkson, P.J. \& Hamilton, J.R., 2000. "Signposting”, A Parameter-driven Task-based Model of the Design Process. Research in Engineering Design, 12(1), pp.18-38.

Eckert, C. M., \& Clarkson, P. J. (2010). Planning development processes for complex products. Research in Engineering Design, 21(3), 153-171.

Eppinger, S.D. \& Browning, T.R., 2012. Design Structure Matrix Methods and Applications Engineering Systems, Cambridge MA: MIT University Press.

Gantt, H.L., 1919. OrganisingOrganizing for work, New York: Harcourt, Brace and Howe.

Gericke, K., Eckert, C. M., \& Wynn, D. (2016). Towards a framework of choices made during the lifecycles of process models. In DS 84: Proceedings of the DESIGN 2016 14th International Design Conference (pp. 1275-1284).

Kerzner, H. \& Grau, N., 2008. Projektmanagement: Ein systemorientierter Ansatz zur Planung und Steuerung, Redline.

Knowledge Based Systems Inc., 2010. IDEF Family of Methods - A Structured Approach to Enterprise Modeling \& Analysis. IDEF Family of Methods. Available at: http://www.idef.com/ [Accessed October 7, 2015].

Kreimeyer, M.F., 2009. A Structural Measurement System for Engineering Design Processes.

O’Donovan, B. et al., 2005. Design planning and modelling. In C. Eckert \& J. Clarkson, eds. Design Process Improvement : A review of current practice. London: Springer, pp. 60-87.

Stacey, M., Eckert, C., \& Hillerbrand, R. (2020). Process models: plans, predictions, proclamations or prophecies?. Research in Engineering Design, 31(1), 83-102.

Trauer, J., Wöhr, F., Eckert, C., Kannengiesser, U., Knippenberg, S., Sankowski, O. (2021). Criteria for selecting design process modelling tools. Proceedings of ICED International Conference on Engineering Design 2021. 